\title{
Supporting Information on the Experimental part \\ Substituent Effect on the Luminescent Properties of A Series of Deep Blue Emitting Mixed Ligand Ir(III) Complexes
}

Yi-Yeol Lyu,${ }^{a, b}$ Younghun Byun,,${ }^{a}$ Ohyun Kwon,,${ }^{a}$ Eunsil Han, ${ }^{a}$ Woo sung Jeon, ${ }^{a}$ Rupasree Ragini Das, ${ }^{* a}$ and Kookheon Char ${ }^{b *}$

${ }^{a}$ Samsung Advanced Institute of Technology, P. O. Box 111, Suwon, 440-600, Korea

${ }^{b}$ School of Chemical and Biological Engineering and NANO System Institute-National Core Research Center, Seoul National University, Seoul, 151-744, Korea

\section{Synthesis of Phosphine Ligands}

(P3): Chlorodiphenylphosphine (30 mmol, $6.62 \mathrm{~g}$ ) was diluted with $300 \mathrm{ml}$ of tetrahydrofuran, and the mixture was cooled to $0^{\circ} \mathrm{C}$. Then, triethylamine $(33 \mathrm{mmol}, 3.34 \mathrm{~g})$ and tri(ethylene glycol) monomethyl ether $(31 \mathrm{mmol}, 5.09 \mathrm{~g})$, were added to this mixture, and it was slowly warmed to room temperature. The reaction mixture was stirred at ambient temperature for $15 \mathrm{hrs}$ under nitrogen environment. The mixture was filtered to remove triethylamine hydrochloride salt, and then the volatile materials were evaporated from the filtrate under the reduced pressure of about 0.1 torr. $100 \mathrm{ml}$ of diethyl ether was added to the resulting product, and the mixture was stirred for $1 \mathrm{hr}$. The mixture was filtered to provide clear and colorless solution. The diethyl ether was evaporated from the 
solution under the reduced pressure of about 0.1 torr at $70^{\circ} \mathrm{C}$. The ligand $(\mathbf{P 3})$ was isolated as a viscous oil $(8.46 \mathrm{~g}, 81 \%) .{ }^{31} \mathrm{P} \mathrm{NMR},\left(300 \mathrm{MHz}, \mathrm{CH}_{2} \mathrm{Cl}_{2}\right): \delta(\mathrm{ppm}) 114.05$.

(P1): It was synthesized in the same manner as used in synthesis of (P3), except that 2methoxyethanol was used instead of tri(ethylene glycol) monomethyl ether. The ligand (P1) was isolated as a viscous oil (6.48 g, $83 \%) .{ }^{31} \mathrm{P} \mathrm{NMR},\left(300 \mathrm{MHz}, \mathrm{CH}_{2} \mathrm{Cl}_{2}\right)$ : $\delta(\mathrm{ppm}) 114.00$

(P350): Ligand (P350) was synthesized in the same manner as (P3), except that poly(ethylene glycol) methyl ether (average Mn, ca. 350) was used instead of tri(ethylene glycol) monomethyl ether. It was isolated as a viscous oil (11.05 g, 69 \%). ${ }^{31} \mathrm{P}$ NMR, (300 $\left.\mathrm{MHz}, \mathrm{CH}_{2} \mathrm{Cl}_{2}\right): \delta(\mathrm{ppm}) 113.96$.

(P3)2: Ligand (P3)2 was synthesized in the same manner as (P3), except that dichlorophenylphosphine $(30 \mathrm{mmol})$, triethylamine $(66 \mathrm{mmol})$ and tri(ethylene glycol) monomethyl ether $(62 \mathrm{mmol})$ was used instead of chlorodiphenylphosphine $(30 \mathrm{mmol})$, triethylamine $(33 \mathrm{mmol})$ and tri(ethylene glycol) monomethyl ether $(31 \mathrm{mmol})$. It was isolated as a viscous oil $(9.52 \mathrm{~g}, 73 \%) .{ }^{31} \mathrm{P} \mathrm{NMR},\left(300 \mathrm{MHz}, \mathrm{CH}_{2} \mathrm{Cl}_{2}\right): \delta(\mathrm{ppm}) 23.55$. 
2. Reaction Scheme of the complexes (P1)DMA, (P3)DMA, P(350)DMA, (P3)F2, (P3)2F2 and (P3)2F2M
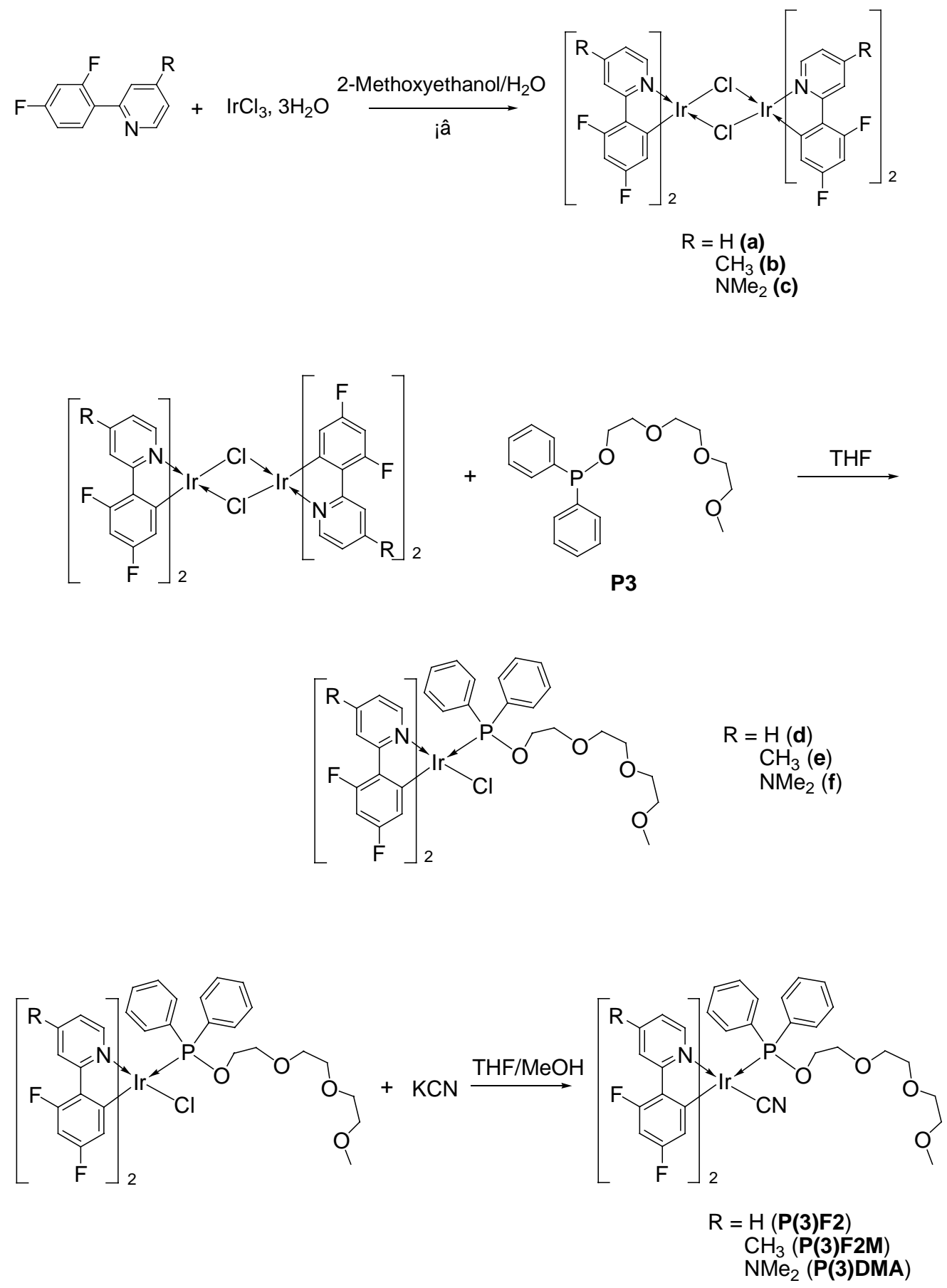
a

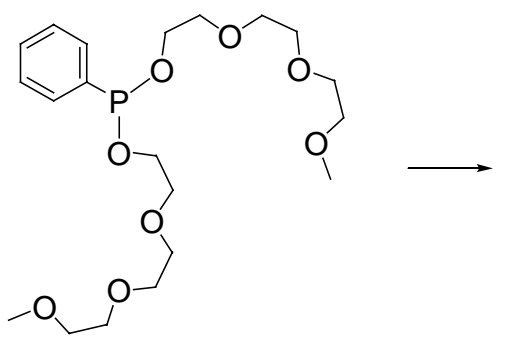

(P3)2
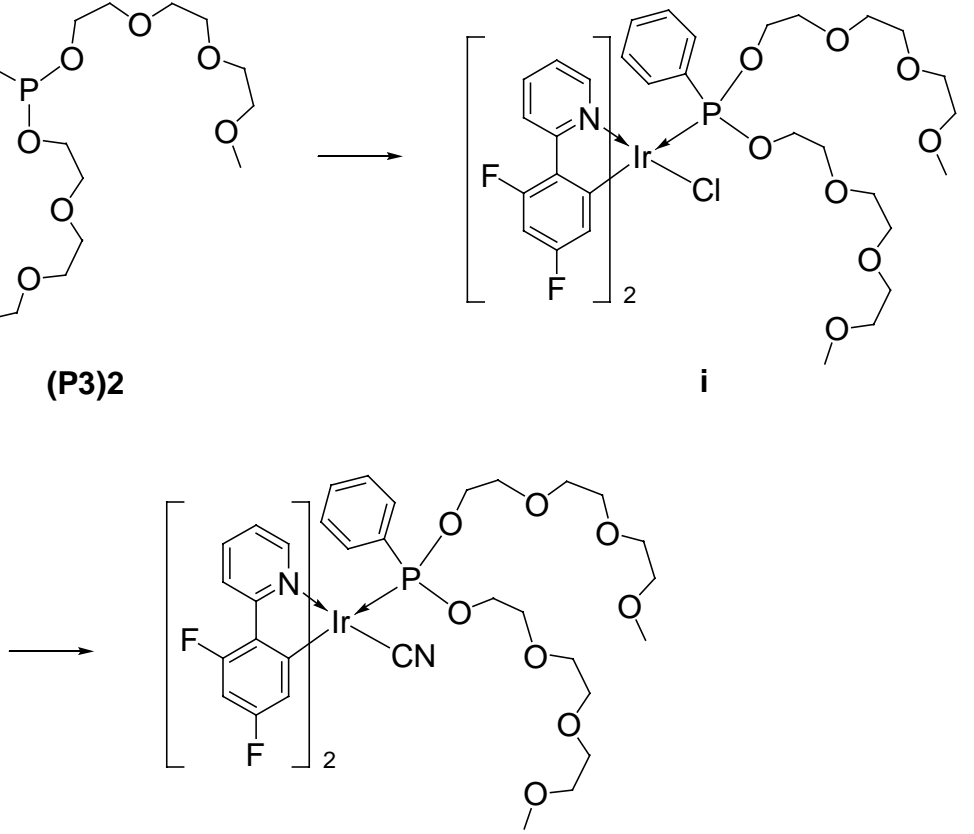

(P3)2F2 


\section{OLED Fabrication}

For the electroluminescence studies, the EL devices were fabricated as described below. A precleaned indium tin oxide (ITO) from Samsung Corning with a sheet resistance of $10 \Omega / \mathrm{cm}^{2}$ was treated with UV-ozone plasma. A $50 \mathrm{~nm}$ thick hole injecting PEDOTPSS (AI4083) from Bayer was spin coated on the ITO surface and dried at $120{ }^{\circ} \mathrm{C}$ for 5 minutes in a glove box. The emissive layers were prepared from the solution of polystyrene (PS, typical Mw: $240 \mathrm{~K}, \mathrm{Mn}: 120 \mathrm{~K}$ ), $\mathrm{mCP}$ and the phosphor dopant with in a weight percent ratio of PS-mCP-dopant (20:74:6) in toluene and spun cast on top of the PEDOT-PSS layer to yield a $40 \mathrm{~nm}$ thick film. A $40 \mathrm{~nm}$ thick BAlq layer was then deposited as a hole blocking as well as electron transporting layer followed by the thermal evaporation at $10^{-6}$ torr. Finally, $\operatorname{LiF}(0.9 \mathrm{~nm})$ and $\mathrm{Al}(200 \mathrm{~nm})$ were deposited as the cathode through a shadow mask by thermal evaporation. The multilayer light emitting devices have the configuration of ITO/PEDOT-PSS $(50 \mathrm{~nm}) / \mathrm{PS}-\mathrm{mCP}$-dopant (20:74:6)/BAlq $(40 \mathrm{~nm}) / \mathrm{LiF}(0.9 \mathrm{~nm}) / \mathrm{Al}(200 \mathrm{~nm})$. Five different EL devices were fabricated using (P1)DMA, (P350)DMA, (P3)F2, (P3)2F2 and (P3)F2M phosphorescent dopants, and the device performances were investigated. All the measurements were made under ambient conditions.

\section{X-ray Crystallography}

Single-crystals of (P1)DMA and (P3)F2M were grown by the slow layer diffusion of methanol or hexane into the methylene chloride solution. Since most crystals lose their structural solvents of crystallization within a few minutes of exposure to air, they were coated with oil, and the intensity data were collected at $-100{ }^{\circ} \mathrm{C}$ with $\mathrm{Mo} \mathrm{K}_{\alpha}$ radiation $(\lambda=$ 
$0.71073 \AA$ ) on a Bruker SMART CCD equipped with a graphite crystal, incident-beam monochromator. All crystallographic data were corrected for the Lorentz and polarization effects, and semi-empirical absorption corrections based on equivalent reflections were applied. All the crystal structures were solved by direct methods and refined by full-matrix least-squares calculations with the SHELXTL-PLUS program package (Ver. 5.1). ${ }^{24}$ All the non-hydrogen atoms were refined anisotropically, and hydrogen atoms were added to their geometrically ideal positions. A summary of the crystals and intensity data is given in Table 1, and details of the crystallographic studies are provided in the Supporting Information.

\section{Measurements}

Cyclic voltammetry (CV) and Osteryoung square wave voltammetry (OSWV) measurements were carried out using BAS 100 B electrochemical analyzer and an EG\&G potentiostat/galvanostat model 283 , respectively. The oxidation potential measurements were carried out in anhydrous acetonitrile solution containing $1 \mathrm{mM}$ electroactive compound and $0.1 \mathrm{M}$ tetrabutylammonium tetrafluorborate $\left(\mathrm{TBABF}_{4}\right)$ as the electrolyte at room temperature in a nitrogen environment. A glassy carbon (diameter: $3.0 \mathrm{~mm}$ ) and a platinum wire were used as working and counter electrodes, respectively. The reference electrode used was $\mathrm{Ag} / \mathrm{AgNO}_{3}(0.1 \mathrm{M})$, and all the potential values were calibrated based on the ferrocene/ferrocenium $\left(\mathrm{Fc} / \mathrm{Fc}^{+}\right)$redox couple. In the case of reduction measurement, a silver wire was used as the pseudo-reference electrode with ferrocene as the internal standard. Reduction measurements were recorded using platinum disk (diameter: $1.6 \mathrm{~mm}$ ) as the working electrodes in anhydrous THF containing $1 \mathrm{mM}$ electroactive compound and 0.1 M tetrabutylammonium hexafluorophosphate (TBAP) as the electrolyte at room 
temperature. The parameters of SWV were as follows: step $\mathrm{E}=25 \mathrm{mV}, \mathrm{SW}$ amplitude $=$ $\pm 10 \mathrm{mV}$.

${ }^{1} \mathrm{H}$ NMR spectra were recorded at $300 \mathrm{MHz}$ with a Bruker FT-NMR spectrometer; chemical shifts were referenced to internal $\mathrm{SiMe}_{4} \cdot{ }^{31} \mathrm{P}$ NMR spectra were recorded at 300 $\mathrm{MHz}$ with a Bruker FT-NMR spectrometer; chemical shifts were referenced to $80 \% \mathrm{H}_{3} \mathrm{PO}_{4}$. Elemental analyses were performed by EA1110, CE Instrument, Italy. All mass spectrometry was performed using a Micromass Quattro II (Micromass, Manchester, U.K.) fitted with a Z-spray ESI (single channel) source. All experiments were conducted in positive ion scan mode. The instrument was set to unit mass resolution on Q1. The instrumental operating parameters were as follows: capillary voltage, $3.0 \mathrm{kV}$; source temperature, $80{ }^{\circ} \mathrm{C}$; desolvation temperature, $250{ }^{\circ} \mathrm{C}$. MassLynx version 3.4 was used for data acquisition and signal processing.

Absorption spectra were monitored with a Shimadzu UV-3150 spectrophotometer and corrected for background absorption. Photoluminescence spectra were obtained by an ISS PC1 spectrofluorometer with Xenon lamp as excitation source. Absolute PL quantum efficiencies of the PMMA films doped with $6 \%$ of the complexes were measured by the integration sphere method using $325 \mathrm{~nm}$ from He-Cd lasing source. Transient PL measurements were recorded from the PMMA films doped with $6 \%$ of the complexes using $325 \mathrm{~nm}$ excitation wavelength from He-Cd laser. The current-voltage characteristics of the EL devices were measured with a PR650 (Spectra Scan) Source Measurement Unit. 